\title{
HPK1 positive expression associated with longer overall survival in patients with estrogen receptor-positive invasive ductal carcinoma-not otherwise specified
}

\author{
JIAOJIAO WANG ${ }^{1 *}$, LIJIE SONG ${ }^{2 *}$, SEN YANG ${ }^{2}$, WEIJIE ZHANG ${ }^{2}$, PENGWEI LU ${ }^{3}$, \\ SHENGLEI LI ${ }^{4}$, HUIXIANG $\mathrm{LI}^{4}$ and LIUXING WANG ${ }^{2}$ \\ Departments of ${ }^{1}$ Ultrasonography, ${ }^{2}$ Oncology, ${ }^{3}$ Breast Surgery and ${ }^{4}$ Pathology, \\ The First Affiliated Hospital of Zhengzhou University, Zhengzhou, Henan 450052, P.R. China
}

Received July 3, 2016; Accepted April 19, 2017

DOI: $10.3892 / \mathrm{mmr} .2017 .7131$

\begin{abstract}
Hematopoietic progenitor kinase 1 (HPK1) belongs to the mitogen activated protein kinase kinase kinase kinase (MAP4K) family of serine/threonine kinases, which have been associated with the incidence and progression of a variety of gastrointestinal malignant tumors in humans. However, the potential association between HPK1 expression and breast cancer, particularly invasive ductal carcinoma-not otherwise specified (IDC-NOS) development, has not yet been examined. To address this gap, the present study aimed to evaluate HPK1 expression in IDC-NOS samples and to determine a relationship with clinical prognostic indicators, such as the expression levels of estrogen receptor (ER), progesterone receptor (PR) and human epidermal growth factor receptor 2 (HER2), as well as overall survival of the patients with IDC-NOS. HPK1 mRNA and protein expression in samples from 148 patients with IDC-NOS were detected using immunohistochemistry, western blotting and reverse transcription-quantitative polymerase chain reaction. A total of 54 out of 148 (36.5\%) samples were HPK1-positive, and 100 out of $148(67.6 \%)$ were ER-positive. Of the latter, 28\% (28/100) were HPK1-positive, and a significant negative association of HPK1 expression with ER positivity was observed $(\mathrm{P}=0.002$; $\mathrm{r}=-0.254)$. In addition, $43.2 \%(64 / 148)$ and $32.4 \%(48 / 100)$ of IDC-NOS tissues were PR- or HER2-positive, respectively; however, neither indicator correlated with HPK1 $(\mathrm{P}=0.109$ and $\mathrm{P}=0.558$, respectively). HPK1 expression, axillary lymph
\end{abstract}

Correspondence to: Professor Liuxing Wang, Department of Oncology, The First Affiliated Hospital of Zhengzhou University, 1 Eastern Jianshe Road, Zhengzhou, Henan 450052, P.R. China

E-mail: 1xwang2006@126.com

*Contributed equally

Key words: invasive ductal carcinoma-not otherwise specified, hematopoietic progenitor kinase 1, estrogen receptor, overall survival node metastasis and tumor-node-metastasis (TNM) stage were identified as independent factors of overall survival (OS) in the ER-positive group $(\mathrm{P}<0.05)$, and HPK1 positivity was associated with increased OS (P=0.048). HPK1 mRNA levels did not differ between IDC-NOS and normal adjacent breast tissues, whereas HPK1 protein levels were lower in IDC-NOS $(\mathrm{P}<0.05)$. These results suggested that HPK1 protein may be a potentially effective IDC-NOS therapeutic target.

\section{Introduction}

According to recent epidemiological studies, invasive ductal carcinoma-not otherwise specified (IDC-NOS) is the most common type of breast cancer and is associated with annual increases in morbidity and mortality $(1,2)$. Estrogen receptor (ER) is the most commonly expressed biomarker in pathological breast cancer and is associated with a good prognosis, despite evident individual differences in the effects of endocrine therapy. The pathogenesis of breast cancer is still unclear and identification of novel potential candidates for breast cancer treatments are urgently required. Targeted therapies for ER-positive breast cancer are a keen area of interest (3).

Hematopoietic progenitor kinase 1 (HPK1), also known as mitogen activated protein kinase kinase kinase kinase 1 (MAP4K1), belongs to the MAP4K family of serine/threonine kinases, which serve vital roles in immune cell responses, inflammatory signaling pathways, stress responses and hematopoietic cell proliferation and apoptosis $(4,5)$; they have also been shown to be involved in human malignancies (6). A previous study demonstrated that HPK1 activation is involved in tyrosine phosphorylation and the formation of inducible complexes with several adaptor proteins. The study also revealed that HPK1 associates with membrane tyrosine kinase receptors, leading to c-Jun $\mathrm{N}$-terminal kinase activation, and serves a critical role in a number of important cellular processes, such as apoptosis (4). Associations between HPK1 expression and the incidence and progression of a variety of malignant tumors in humans have been reported previously. For example, HPK1 was revealed to be a downstream target of the tumorigenesis suppressor, programmed cell death protein 
4 , and serves a role in colon carcinoma cell invasion (7). In addition, a lack of HPK1 expression was revealed to promote the development and tumorigenesis of pancreatic ductal adenocarcinoma (8). Other studies have indicated that HPK1 may inhibit the proliferation of a lung cancer cell line, as well as the infiltration and metastasis of non-small cell lung carcinoma (NSCLC) cells $(9,10)$. Hsa-microRNA-96 has also been revealed to upregulate HPK1, which may function as a promising diagnostic marker in human bladder urothelial carcinomas (11). However, a potential association between HPK1 expression and breast cancer, particularly IDC-NOS development, has not been examined either domestically or internationally. To address this gap, the present study evaluated HPK1 expression in IDC-NOS samples and investigated the relationship of HPK1 protein expression with the expression of clinicopathological biomarkers, such as ER, progesterone receptor (PR) and human epidermal growth factor receptor 2 (HER2), as well as with overall survival (OS). The results demonstrated that HPK1 is closely associated with the prognosis of ER-positive breast cancer and that it may function as a tumor suppressor; thus, its loss may serve a critical role in tumorigenesis.

\section{Materials and methods}

Patients. The present study involved a retrospective examination of 148 consecutive female patients (between January 2009 and July 2010 at the First Affiliated Hospital of Zhengzhou University, Zhengzhou, China) with breast cancer confirmed by pathology that underwent modified radical mastectomy without preoperative chemotherapy or radiotherapy. All patients were classified as having stage I-II or III of the disease, according to the American Joint Committee on Cancer standards. According to National Comprehensive Cancer Network guidelines (12), postoperative radiotherapy and routine chemotherapy were administered following mammary gland resection. Patients with immunohistochemically confirmed ER-positive IDC-NOS also received regular endocrine therapy. Clinical pathology and follow-up data integrity were maintained; pregnant or lactating patients were excluded. All patient followed-ups were conducted at the First Affiliated Hospital of Zhengzhou University until July 2015. The associations between HPK1 protein expression and the clinicopathological features in patients with IDC-NOS were recorded (Table I). Follow-up information was obtained via telephone interviews, outpatient services and a review of the medical records. Follow-ups also evaluated postoperative tumor recurrence and metastasis, auxiliary therapy status, patient survival status and time and cause of death. Tumor-node-metastasis (TNM) staging was determined according to the 7 th edition of the International Cancer Coalition and American Cancer Association Joint TNM Staging System (13). Histological classification was determined according to the Miller-Payne histological grading system (14). The present study was approved by the Institutional Ethics Review Board of Zhengzhou University (Zhengzhou, Henan, China) and written informed consent was obtained from all of the patients.

General conditions. The mean patient age was 52 years (range, 29-78 years). The final survival assessment was performed in
September 2015. A minimum of 5 years of follow-up information was available for all of the surviving patients; the median follow-up durations for the 109 surviving patients and the 39 patients who perished during the follow-up period were 65 months (range, 62-80 months) and 43 months (range, 1-79 months), respectively ( $\mathrm{n}=148$ patients in total). A total of 114 patients were classified as having TNM stage I-II IDC-NOS, and 34 were classified as stage III. There were 87 patients with well/moderate histological differentiation, whereas the remaining 61 patients had poor differentiation. In addition, 61 patients were identified with axillary lymph node metastasis.

Tissue samples and immunohistochemical staining. Tissue sections $(3-\mu \mathrm{m})$ used in the present study were obtained from formalin-fixed, paraffin-embedded archival tissue microarray blocks containing mammectomy specimens, including cancerous tissue and matched normal adjacent tissue (NAT), from the aforementioned patients with stage I-III IDC-NOS. Unstained sections from the tissue microarray blocks were subjected to immunohistochemical streptavidin-horseradish peroxidase staining to detect protein expression. Sections were deparaffinized with $100 \%$ xylene and rehydrated with graded alcohol (95\% alcohol for $1 \mathrm{~min}, 90 \%$ alcohol for $1 \mathrm{~min}$, $80 \%$ alcohol for $1 \mathrm{~min}, 70 \%$ alcohol for $1 \mathrm{~min}, 60 \%$ alcohol for $1 \mathrm{~min}, 50 \%$ alcohol for $1 \mathrm{~min}$ and PBS for $5 \mathrm{~min}$ ). Antigen retrieval was performed using microwave treatment for $10 \mathrm{~min}$ in $10 \mathrm{mM}$ sodium citrate buffer ( $\mathrm{pH} \mathrm{6.0).} \mathrm{Endogenous}$ peroxidase activity was quenched by incubating the sections in $100 \%$ methanol with $6 \%$ hydrogen peroxide. Slides were then incubated with antibodies for $30 \mathrm{~min}$ at $37^{\circ} \mathrm{C}$ [anti-HPK1 antibody (cat. no. AF1538a; 1:100; Abgent, Inc., San Diego, CA, USA), anti-ER antibody (cat. no. 21244-1-AP; 1:200), anti-PR antibody (cat. no. 66300-1-Ig; 1:200) and anti-HER2 antibody (cat. no. 60311-1-Ig; 1:100; all Wuhan Sanying Biotechnology, Wuhan, China), washed with PBS and incubated with a secondary rabbit anti-goat antibody $(1: 100$; cat. no. PV-9003; ZSGB-BIO; OriGene Technologies, Inc., Beijing, China) at room temperature for $60 \mathrm{~min}$. Staining was completed following a $10 \mathrm{~min}$ incubation at room temperature with a freshly prepared substrate-chromogen solution (20 $\mu \mathrm{l}$ DAB chromogen per $1 \mathrm{ml}$ of PBS), which resulted in a brown-colored precipitate at the antigen site. Slides were subsequently counterstained with $50 \mu 1$ hematoxylin for $15 \mathrm{~min}$ at room temperature, then dehydrated with graded alcohol $(50 \%$ alcohol for $1 \mathrm{~min}, 60 \%$ alcohol for $1 \mathrm{~min}, 70 \%$ alcohol for $1 \mathrm{~min}, 80 \%$ alcohol for $1 \mathrm{~min}, 90 \%$ alcohol for $1 \mathrm{~min}, 95 \%$ alcohol for $1 \mathrm{~min}$ and $100 \%$ alcohol for $1 \mathrm{~min}$ ) and mounted with $100 \%$ xylene for $10 \mathrm{~min}$. These experiments were performed in triplicate. Phosphate-buffered saline solution was used in place of the primary antibody for the blank control. During analysis, five randomly selected fields per section were viewed under a light microscope (CX41; Olympus Corporation, Tokyo, Japan) at x400 magnification. Image Pro Plus software version 6.0 (Media Cybernetics, Inc., Rockville, MD, USA) was used for analysis.

Immunohistochemical evaluation. To investigate the association between HPK1 protein expression and the expression of ER, PR and HER2 in tumors, immunohistochemistry was 
performed to examine the expression of HPK1, ER, PR and HER2 in tumors. The focus of the present study was HPK1 expression, therefore only HPK1 expression was examined in NATs. For each enrolled patient, two sections were selected for the analysis, the cancerous breast tissue and the paired NAT. Positive staining was defined as the presence of a granular brown substance located in the cytoplasm for HPK1, in the membrane for HER 2 and in the nucleus for ER and PR. Both the intensity and the frequency of immunostained cancer cells were considered: frequency was scored as $0,1,2$ or 3 when the percentage of positive cells was $<10,11-20,21-50$ or $>50 \%$, respectively; and intensity was scored as $0,1,2$ or 3 for no, weak, moderate or strong staining, respectively. Final immunohistochemical staining grades were determined by multiplying the intensity by the frequency; a value of $0-1$ was considered negative, and a value $\geq 2$ was considered positive. All immunohistochemically stained slides were reviewed independently in a double-blind manner by two experienced pathologists.

Reverse transcription-quantitative polymerase chain reaction (RT-qPCR) of HPK1 mRNA expression. The 100 tissue samples used for RT-qPCR were selected from among the ER-positive tissues. Specimens were prepared from frozen tissue blocks containing cancer tissues and NATs. Microdissection was performed to separate the cancerous and normal tissues prior to the extraction of total RNA using TRIzol Reagent (Invitrogen; Thermo Fisher Scientific, Inc., Waltham, MA, USA) according to the manufacturer's protocol. Each of the 100 samples was $50-100 \mathrm{mg}$. The concentration and purity of all total RNA samples was verified using a NanoDrop 2000 (Thermo Fisher ${ }^{\mathrm{TM}}$ Scientific, Inc.). cDNA was obtained using a PrimeScript RT reagent kit (Takara Bio, Inc., Otsu, Japan) according to manufacturer's instructions. Briefly, samples containing $1 \mu \mathrm{g}$ total RNA were incubated with $1 \mu \mathrm{l}$ gDNA Eraser, $2 \mu \mathrm{l}$ 5X cDNA Eraser Buffer and RNase free $\mathrm{dH}_{2} \mathrm{O}$ at $42^{\circ} \mathrm{C}$ for $2 \mathrm{~min}$. The SYBR enzyme mix (Takara Bio, Inc.) was added to anneal the total RNA sample, then the reaction was incubated for $15 \mathrm{~min}$ at $37^{\circ} \mathrm{C}$. cDNA was then used to detect the expression levels of HPK1. cDNA was used as the template for RT-qPCR using SYBR Premix ExTaq II (Takara Bio, Inc.), according to the manufacturer's instructions, on the ABI PRISM 7300 sequence system (Applied Biosystems; Thermo Fisher Scientific, Inc.). Samples were amplified using the following thermocycling conditions: 40 cycles of $95^{\circ} \mathrm{C}$ for $30 \mathrm{sec}$, $95^{\circ} \mathrm{C}$ for $5 \mathrm{sec}$ and $60^{\circ} \mathrm{C} 30 \mathrm{sec}$. The abundance of mRNA for each gene of interest was normalized to $\beta$-actin mRNA. The following primers were designed by Sangon Biotech Co., Ltd. (Shanghai, China): HPK1, forward 5'-TCTGGAAGC ATGGAGTGCAG-3', reverse 5'-ACTACAGGCCTGGGG GAG-3'; $\beta$-actin, forward 5'-TACCTCATGAAGATCCTC ACC-3', reverse 5'-TTTCGTGGATGCCACAGGAC-3'. Each RT-qPCR was performed in triplicate, and the mean value was used to calculate the ratio of HPK1 to $\beta$-actin; results were quantified using the $2^{-\Delta \Delta \mathrm{Cq}}$ method (15).

Western blot analysis of HPK1 protein expression. All tissue samples used for western blotting were from the same samples used for RT-qPCR. Following microdissection to separate cancerous and normal tissues, total proteins were extracted by adding lysis buffer (cat. no. p0013C; Biyuntian, Jiangsu, China) with proteinase inhibitors cocktail 1 (cat. no. P8340-1ML; Sigma; Merck KGaA, Darmstadt, Germany) and phosphatase inhibitors cocktail 2 (cat. no. P5726-1ML; Sigma; Merck $\mathrm{KGaA}$ ). Protein concentration was determined using a bicinchoninic acid kit (cat. no. P0006; Biyuntian) according to the manufacturer's instructions. Equal amounts $(50 \mu \mathrm{g})$ of protein were loaded on to a $10 \%$ SDS-PAGE gel. Following electrophoresis, the proteins were blotted to a PVDF membrane (cat. no. 1060000; Amersham; GE Healthcare, Chicago, IL, USA; $0.2 \mu \mathrm{M}$ NC). The membrane was blocked in 5\% non-fat milk at room temperature for $1 \mathrm{~h}$ and then incubated with primary antibodies overnight at $4^{\circ} \mathrm{C}$. The primary antibodies used were as follows: anti-HPK1 (cat. no. AF1538a; Abgent, Inc.; 1:1,000) and anti- $\beta$-actin (cat. no. 4970; Cell Signaling Technology, Inc., Danvers, MA USA; 1:1,000). They were then incubated with 5\% bovine serum albumin (cat. no. \#V900933-100G; Sigma; Merck KGaA; 50 g added to TBST buffer to a final volume of 1 l) diluted secondary antibodies [anti-mouse IgG $(\mathrm{H}+\mathrm{L})$-horseradish peroxidase (HRP) conjugated (cat. no. ZB-2305); anti-rabbit IgG (H+L)-HRP conjugated (cat. no. ZB-2301); OriGene Technologies, Inc., Beijing, China; 1:5,000] for $2 \mathrm{~h}$ at $37^{\circ} \mathrm{C}$. The blot was detected using an enhanced chemiluminescence detection kit (Amersham; GE Healthcare Life Sciences, Little Chalfont, UK). The band density of the target protein was calculated using the Bio-Rad Quantity One 1-D Analysis Software (version 4.6.9; Bio-Rad Laboratories, Inc., Hercules, CA, USA). The results were normalized to $\beta$-actin. These experiments were performed in triplicate.

Statistical analysis. Data processing and statistical analysis were performed using the SPSS 21.0 statistical analysis package (IBM Corp., Armonk, NY, USA). The $\chi^{2}$ test was used for numerical data. Bivariate associations between ordinal variables were assessed using Spearman's correlation (exact version). The Kaplan-Meier method followed by the log-rank test was used to estimate survival outcomes. A Cox proportional hazards model was used for multivariate analysis. $\mathrm{P}<0.05$ was considered to indicate a statistically significant difference.

\section{Results}

Immunohistochemical detection of HPK1, ER, PR and HER2 protein expression in breast tissues. Positive HPK1 immunostaining was observed in the cytoplasm in 54 out of 148 (36.5\%) IDC-NOS tumor samples (Fig. 1); the remaining 94 $(63.5 \%)$ tumors were negative for HPK1 staining. Among the adjacent paired NATs, 119 out of $148(80.4 \%)$ were positive for HPK1 staining and 29 (19.6\%) were negative. The difference in expression between tumor and paired NATs was statistically significant $\left(\chi^{2}=10.636 ; \mathrm{P}=0.001\right)$. In addition, among the 148 tumors: 100 (67.6\%) were ER positive and 48 (32.4\%) were ER negative; 64 (43.2\%) were PR positive and 84 (56.8\%) were PR negative; and 48 (32.4\%) were HER2 positive and $100(67.6 \%)$ were HER2 negative.

HPK1 mRNA expression in the ER-positive breast tissues. HPK1 mRNA expression levels in the ER-positive IDC-NOS tissues relative to paired NATs ranged between 0.8256 and 
Table I. Association between HPK1 protein expression and clinicopathological features in patients with invasive ductal carcinoma-not otherwise specified.

\begin{tabular}{|c|c|c|c|c|c|}
\hline \multirow[b]{2}{*}{ Clinicopathological feature } & \multirow[b]{2}{*}{$\mathrm{n}$} & \multicolumn{2}{|c|}{ HPK1 expression } & \multirow[b]{2}{*}{$\chi^{2}$} & \multirow[b]{2}{*}{ P-value } \\
\hline & & Positive & Negative & & \\
\hline \multicolumn{6}{|l|}{ Age (years) } \\
\hline$<50$ & 76 & 32 & 44 & & \\
\hline$\geq 50$ & 72 & 22 & 50 & 2.128 & 0.145 \\
\hline \multicolumn{6}{|l|}{ TNM stage } \\
\hline I-II & 114 & 52 & 62 & & \\
\hline III & 34 & 2 & 32 & 17.840 & $<0.001$ \\
\hline \multicolumn{6}{|c|}{ Axillary lymph node metastasis } \\
\hline Negative & 87 & 35 & 52 & & \\
\hline Positive & 61 & 19 & 42 & 1.276 & 0.259 \\
\hline \multicolumn{6}{|l|}{ Histological grade } \\
\hline Well/moderate & 87 & 45 & 42 & & \\
\hline Poor & 61 & 9 & 52 & 21.149 & $<0.001$ \\
\hline
\end{tabular}

HPK1, hematopoietic progenitor kinase 1; TNM, tumor-node-metastasis.

Table II. Association between HPK1 protein expression, and ER, PR and HER2 expression in patients with invasive ductal carcinoma-not otherwise specified.

\begin{tabular}{|c|c|c|c|c|c|}
\hline \multirow[b]{2}{*}{ Clinicopathological feature } & \multirow[b]{2}{*}{$\mathrm{n}$} & \multicolumn{2}{|c|}{ HPK1 expression } & \multirow[b]{2}{*}{$\chi^{2}$} & \multirow[b]{2}{*}{ P-value } \\
\hline & & Positive & Negative & & \\
\hline \multicolumn{6}{|l|}{ ER expression } \\
\hline Negative & 48 & 26 & 22 & & \\
\hline Positive & 100 & 28 & 72 & 9.582 & 0.002 \\
\hline \multicolumn{6}{|l|}{ PR expression } \\
\hline Negative & 84 & 26 & 58 & & \\
\hline Positive & 64 & 28 & 36 & 2.567 & 0.109 \\
\hline \multicolumn{6}{|l|}{ HER2 expression } \\
\hline Negative & 100 & 35 & 65 & & \\
\hline Positive & 48 & 19 & 29 & 0.294 & 0.558 \\
\hline
\end{tabular}

ER, estrogen receptor; HER2, human epidermal growth factor receptor 2; HPK1, hematopoietic progenitor kinase 1; PR, progesterone receptor.

$1.3298(1.026 \pm 0.042)$; no statistically significant differences were identified ( $\mathrm{P}>0.05$; Fig. 2).

HPK1 protein expression in ER-positive breast tissues. Significantly higher HPK1 protein expression levels were detected in ER-positive IDC-NOS tumors relative to paired NATs. HPK1 protein expression levels were analyzed in 20 patients randomly selected from the ER-positive IDC-NOS group $(n=100)$, the average values were as follows: NATs, $0.302 \pm 0.018$; IDC-NOS, $0.1453 \pm 0.018$ ( $\mathrm{P}=0.036$; Fig. 3A). The results include the analysis from all 20 patients however, 4 of these patients were randomly chosen and their data are presented as a representation of the results in Fig. 3B.
Relationship between HPK1 expression and clinicopathological factors in patients with IDC-NOS. HPK1 protein expression was demonstrated to associate with the tumor histological grade and TNM stage in patients with IDC-NOS $(\mathrm{P}<0.001$; Table I). HPK1 protein expression was significantly lower in TNM stage III tumors compared with stage I-II and in tumors with poor histological differentiation compared with well or moderately differentiated tumors.

Relationship between HPK1 protein expression and prognostic indicators. The expression of HPK1 protein in IDC-NOS tissues was compared with expression of the prognostic indicators ER, PR and HER2 (Table II). A 


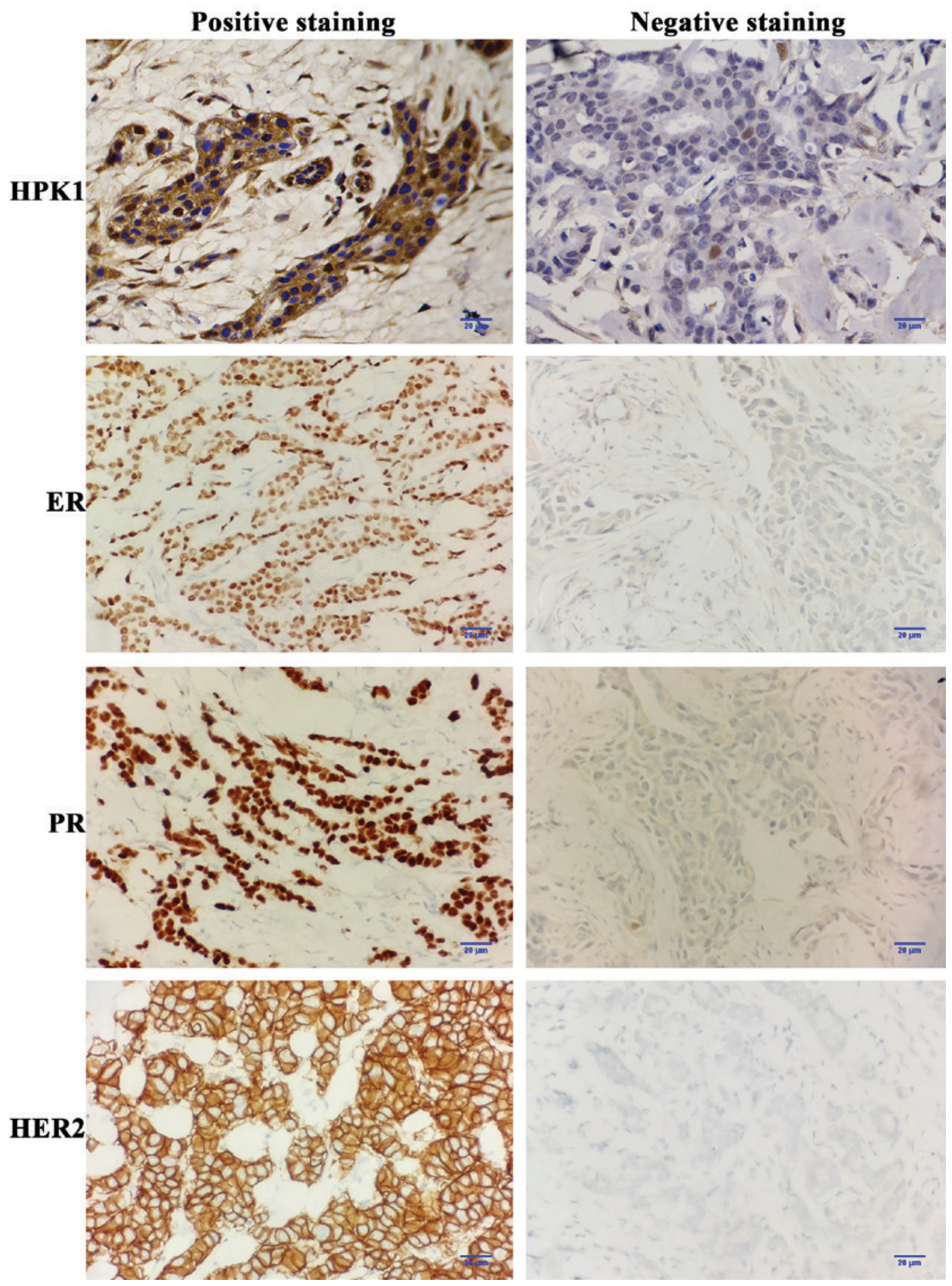

Figure 1. Immunohistochemical staining of invasive ductal carcinoma-not otherwise specified tissues. Examples of positive and negative staining tissues are displayed; a positive signal was defined as the presence of a granular brown substance in the cytoplasm for HPK1, in the nucleus for ER and PR, and in the membrane for HER2. Magnification, $\mathrm{x} 400$; scale $\mathrm{bar}=20 \mu \mathrm{m}$. ER, estrogen receptor; HER2, human epidermal growth factor receptor 2; HPK1, hematopoietic progenitor kinase 1; PR, progesterone receptor.

negative correlation was observed between HPK1 and ER expression $\left(\chi^{2}=9.582, \mathrm{P}=0.002, \mathrm{r}=-0.254\right)$. No correlation was observed between HPK1 expression and PR or HER2 expression $\left(\chi^{2}=2.567\right.$ and 0.294 , respectively; $\mathrm{P}=0.109$ and 0.558 , respectively).

Analysis of survival prognosis. The 5-year OS rate for the ER-positive group $(\mathrm{n}=100)$ was $81.0 \%$ when compared with
$58.3 \%$ for the ER-negative group as a whole ( $\mathrm{n}=48$; Table III). No correlation was observed between HPK1 expression and prognosis in the ER-negative group $(n=48)$. The ER-negative group was subsequently divided into two groups according to HPK1 expression. For the ER-negative/HPK1-positive $(n=26)$ and ER-negative/HPK1-negative $(n=22)$ groups, the 5 -year OS rate was 69.2 and $45.5 \%$, respectively, which was not significantly different (Table IV). In the univariate 
Table III. Analysis of estrogen receptor expression in association with the overall survival rate in patients with invasive ductal carcinoma-not otherwise specified.

\begin{tabular}{lcccccc}
\hline \multirow{2}{*}{$\begin{array}{l}\text { ER } \\
\text { expression }\end{array}$} & $\begin{array}{c}\text { Number of } \\
\text { patients (n) }\end{array}$ & Survival (n) & Fatality (n) & $\begin{array}{c}\text { OS rate } \\
(\%)\end{array}$ & $\chi^{2}$ & P-value \\
\cline { 3 - 5 } & 100 & 81 & 19 & 81.0 & 8.586 & 0.003 \\
Positive & 48 & 28 & 20 & 58.3 & & \\
Negative & & & & & & \\
\hline
\end{tabular}

ER, estrogen receptor; OS, overall survival.

Table IV. Analysis of hematopoietic progenitor kinase 1 expression in association with the overall survival rate in patients with estrogen receptor-negative invasive ductal carcinoma-not otherwise specified.

\begin{tabular}{lcccccr}
\hline \multirow{2}{*}{$\begin{array}{l}\text { HPK1 } \\
\text { expression }\end{array}$} & $\begin{array}{c}\text { Number of } \\
\text { patients (n) }\end{array}$ & Survival (n) & Fatality (n) & $\begin{array}{c}\text { OS rate } \\
(\%)\end{array}$ & $\chi^{2}$ & P-value \\
\cline { 3 - 5 } Positive & 26 & 18 & 8 & 69.2 & 2.772 & 0.096 \\
Negative & 22 & 10 & 12 & 45.5 & & \\
\hline
\end{tabular}

HPK1, hematopoietic progenitor kinase 1; OS, overall survival.

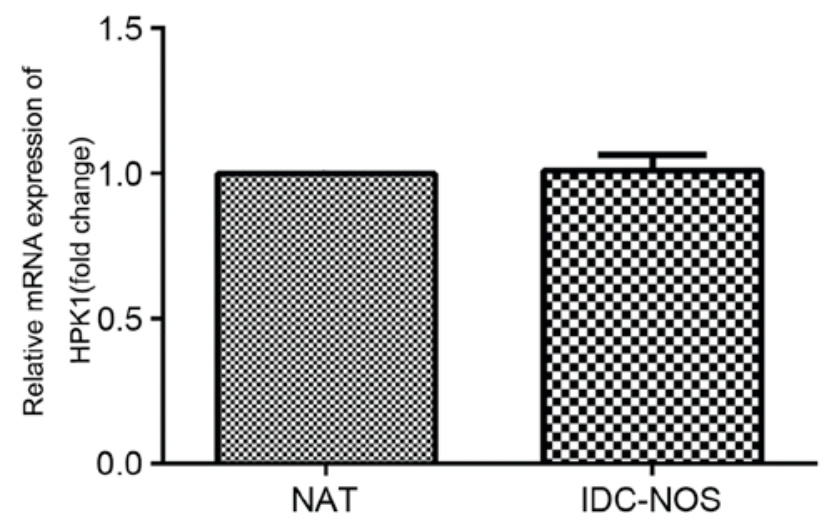

Figure 2. HPK1 mRNA expression levels in IDC-NOS tissues and adjacent paired NATs. HPK1 mRNA expression levels in the IDC-NOS group were $0.9836 \pm 0.1268$. No significant differences were identified following reverse transcription-quantitative polymerase chain reaction analysis $(\mathrm{P}>0.05)$. Data are presented as the mean \pm standard deviation. HPK1, hematopoietic progenitor kinase 1; IDC-NOS, invasive ductal carcinoma-not otherwise specified tissues; NAT, normal adjacent tissue.

analysis of the ER-positive group (Table V), the low OS rate correlated significantly with TNM stage III $(\mathrm{P}<0.001)$, poor histological differentiation grade $(\mathrm{P}<0.05)$, positive axillary lymph node metastasis $(\mathrm{P}<0.001)$ and negative HPK1 expression $(\mathrm{P}<0.05)$, according to a log-rank test. No significant correlations were identified between OS rate and the other clinicopathological parameters $(P>0.05)$. In the multivariate analysis, negative HPK1 expression was associated with a lower OS $(\mathrm{P}=0.011)$ independent of the TNM stage III, positive axillary lymph node metastasis status and poor histological grade (Table VI).
Relationship between HPK1 protein expression and survival duration. The Kaplan-Meier survival curve for the ER-positive group revealed a longer OS duration for patients with HPK1-positive tumors compared with patients with HPK1-negative tumors ( $\mathrm{P}<0.05$; Fig. 4).

\section{Discussion}

Breast cancer is a highly malignant and molecularly heterogeneous disease that presents a serious threat to the lives and health of women worldwide, and the incidence rate is increasing annually $(1,2)$. IDC-NOS is the most common pathological type of breast cancer, and $\sim 70 \%$ of IDC-NOS cases are ER-positive. ER is expressed in the nuclei of normal mammary epithelial cells and affects breast cell growth and differentiation; however, ER expression tends to decrease or disappear during the malignant transformation of mammary gland epithelial cells. In patients with ER-positive breast cancer, the tumor cells have been reported to be well differentiated and slow to proliferate; in addition, disease progression is slow, and the tumors respond relatively well to endocrine therapy (16). However, the prognosis of patients in the context of endocrine therapy varies according to individual patient differences.

Tumorigenesis involves a spectrum of cellular events and processes. Activation of the MAPK and c-Jun N-terminal kinase survival and antiapoptotic signaling pathways is a crucial step in tumor cells (17). HPK1, an important member of the MAP4K family of proteins, has previously been reported to serve an important role in tumorigenesis and disease progression through its multiple roles in immunity and inflammation (4), as well as hematopoietic 
Table V. Univariate analysis of clinicopathological factors related to OS in patients with estrogen receptor-positive invasive ductal carcinoma-not otherwise specified.

\begin{tabular}{|c|c|c|c|c|c|c|}
\hline \multirow[b]{2}{*}{ Clinicopathological feature } & \multirow[b]{2}{*}{$\mathrm{n}$} & \multicolumn{2}{|c|}{ Prognosis } & \multirow[b]{2}{*}{ OS rate $(\%)$} & \multirow[b]{2}{*}{$\chi^{2}$} & \multirow[b]{2}{*}{ P-value } \\
\hline & & Survival (n) & Fatality (n) & & & \\
\hline \multicolumn{7}{|l|}{ Age (years) } \\
\hline$<50$ & 52 & 43 & 9 & 82.7 & & \\
\hline$\geq 50$ & 48 & 38 & 10 & 79.2 & 0.252 & 0.616 \\
\hline \multicolumn{7}{|l|}{ TNM stage } \\
\hline I-II & 88 & 77 & 11 & 87.5 & & \\
\hline III & 12 & 4 & 8 & 33.3 & 43.054 & $<0.001$ \\
\hline \multicolumn{7}{|l|}{ Histological grade } \\
\hline Well/moderate & 61 & 53 & 8 & 86.9 & & \\
\hline Poor & 39 & 28 & 11 & 71.8 & 4.508 & 0.034 \\
\hline \multicolumn{7}{|c|}{ Axillary lymph node metastasis } \\
\hline Positive & 38 & 22 & 16 & 57.9 & & \\
\hline Negative & 62 & 59 & 3 & 95.2 & 20.653 & $<0.001$ \\
\hline \multicolumn{7}{|l|}{ PR expression } \\
\hline Positive & 37 & 29 & 8 & 78.4 & & \\
\hline Negative & 63 & 52 & 11 & 82.5 & 0.14 & 0.709 \\
\hline \multicolumn{7}{|l|}{ HER2 expression } \\
\hline Positive & 27 & 23 & 4 & 85.2 & & \\
\hline Negative & 73 & 58 & 15 & 79.5 & 0.288 & 0.591 \\
\hline \multicolumn{7}{|l|}{ HPK1 expression } \\
\hline Positive & 28 & 24 & 4 & 85.7 & & \\
\hline Negative & 72 & 57 & 15 & 79.2 & 3.919 & 0.048 \\
\hline
\end{tabular}

HER2, human epidermal growth factor receptor 2; HPK1, hematopoietic progenitor kinase 1; OS, overall survival; PR, progesterone receptor; TNM, tumor-node-metastasis.

Table VI. Multivariate analysis of clinicopathological factors related to overall survival in patients with estrogen receptor-positive invasive ductal carcinoma-not otherwise specified.

\begin{tabular}{lcrrrrr}
\hline & & \multicolumn{2}{c}{$95.0 \%$ CI } & & \\
Risk factor & OR & Lower & Upper & B & P-value \\
\hline TNM stage (III vs. I-II) & 3.093 & 1.447 & 6.612 & 1.129 & $0.004^{\text {a }}$ \\
Axillary lymph node metastasis (Positive vs. negative) & 5.159 & 1.146 & 23.225 & 1.641 & $0.033^{\text {b }}$ \\
Histopathological grade (poor vs. well/moderate) & 2.394 & 0.94 & 6.096 & 0.873 & $0.067^{\mathrm{c}}$ \\
HPK1 expression (positive vs. negative) & 0.132 & 0.028 & 0.632 & -2.021 & $0.011^{\mathrm{d}}$ \\
\hline
\end{tabular}

CI, confidence interval; B, partial regression coefficient; HPK1, hematopoietic progenitor kinase 1; OR, odds ratio; TNM, tumor-node-metastasis.

cell processes (5). Notably, a loss of HPK1 protein expression was demonstrated to be significantly correlated with the progression of pancreatic intraepithelial neoplasia and the development of invasive pancreatic ductal adenocarcinomas, and HPK1 was revealed to be absent from $>95 \%$ pancreatic cancers as a result of proteasome-mediated degradation (8). In addition, HPK1 was reported to be a crucial component of prostaglandin E2-mediated suppression of the antitumor immune response in NSCLCs (9) A previous study demonstrated that HPK1 partly antagonized the HPK1-interacting protein of $55 \mathrm{kDa}$-mediated oncogenic pathway and suppressed tumorigenesis-related processes, such as promoting proliferation, colony formation, migration and invasion, in lung cancer cells (10). Therefore, HPK1 may be useful as a therapeutic target in cancers (18). To the best of our knowledge, the present study is the first domestic 
A

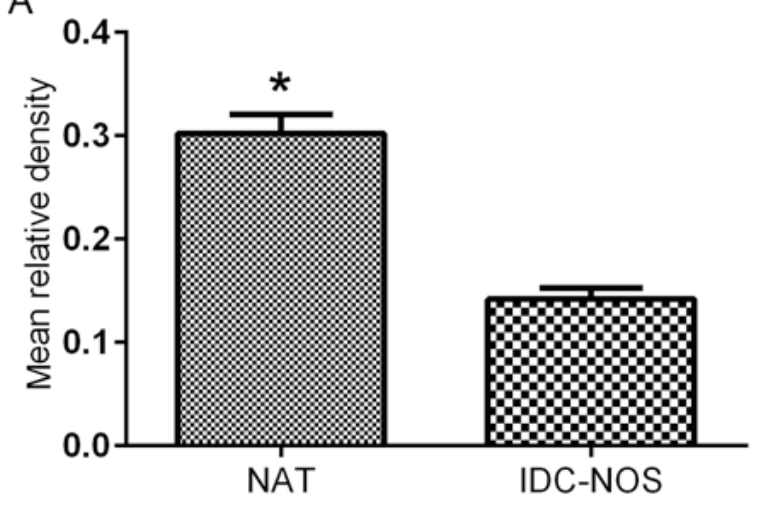

B
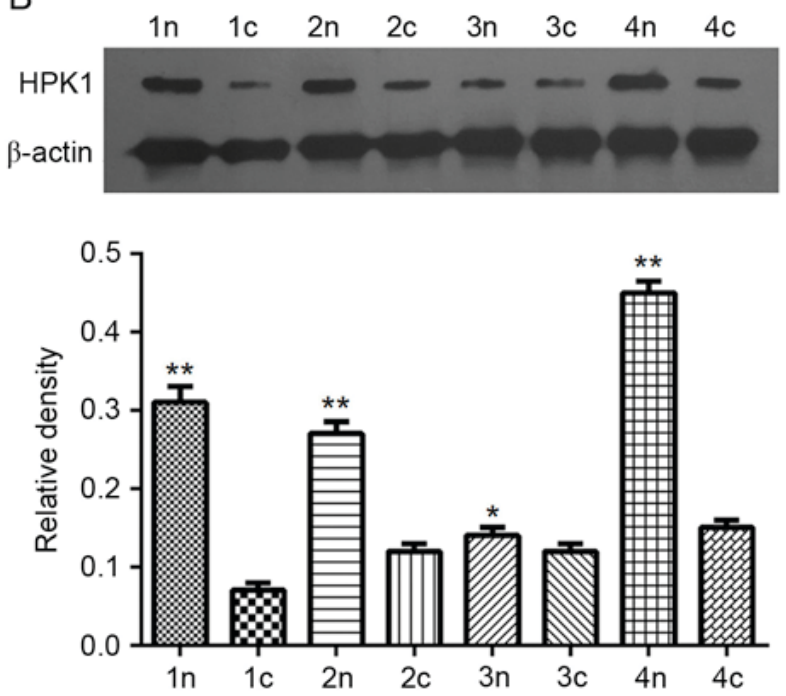

Figure 3. HPK1 protein expression in ER-positive IDC-NOS tissues and paired normal tissues. Western blot analysis was used to determine the HPK1 protein expression levels in tissue samples of 20 patients randomly selected from the ER-positive IDC-NOS group; the bar graph represents the densitometric analysis normalized to $\beta$-actin. (A) The average HPK1 protein expression levels of these 20 patients were as follows: NAT, $0.302 \pm 0.018$ IDC-NOS, 0.1453 \pm 0.018 . ${ }^{*} \mathrm{P}<0.05 \mathrm{vs}$. IDC-NOS. (B) A total of 4 of these 20 patients were randomly chosen and are presented in the figure as a representation of the results. " $\mathrm{P}<0.05$ and ${ }^{* *} \mathrm{P}<0.01$ vs. $\mathrm{c}$ tissues. Data are presented as the mean \pm standard deviation. c, cancerous tissue; ER, estrogen receptor; HPK1, hematopoietic progenitor kinase 1; IDC-NOS, invasive ductal carcinoma-not otherwise specified tissues; $n$, normal adjacent tissue.

report to discuss the role of HPK1 in human breast cancer. In particular, a significant negative association was made between HPK1 protein expression (which was significantly higher in NATs compared with paired IDC-NOS tissues) and ER positivity, as well as a positive association between HPK1 expression and survival duration. These data suggest that HPK1 may have inhibitory effects on tumor cells.

In pancreatic cancer, the cullin $7 / \mathrm{F}$-box and WD-40 domain-containing protein 8 ubiquitin ligase complex was demonstrated to target HPK1 within the MAPK pathway for degradation through the $26 \mathrm{~S}$ proteasome (19); this negative feedback loop acts to restrain HPK1 activity by reducing or even eliminating HPK1 protein expression, thus promoting cancer cell proliferation. This previous report may explain the

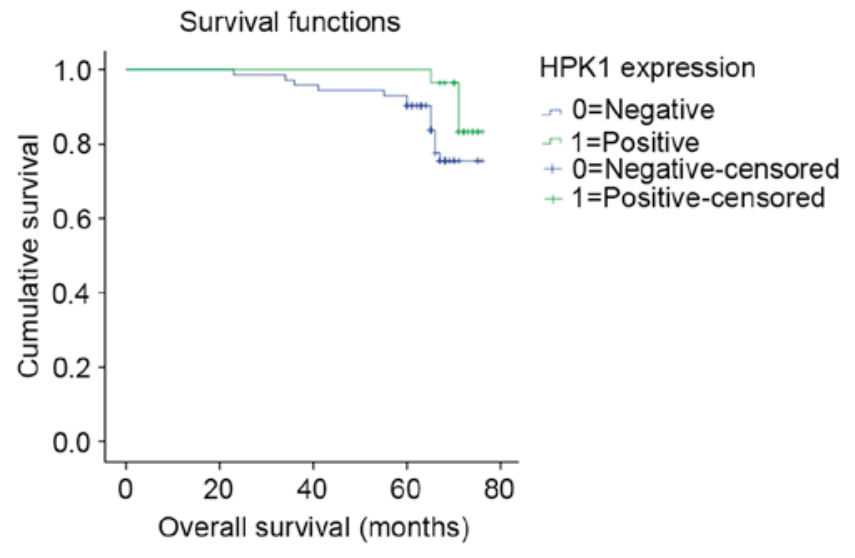

Figure 4. HPK1 expression and overall survival. Kaplan-Meier analysis of survival among patients with estrogen receptor-positive invasive ductal carcinoma-not otherwise specified. HPK1, hematopoietic progenitor kinase 1 ; censored, mortality.

lack of difference in HPK1 mRNA expression in tissues from IDC-NOS tumors relative to paired NATs in the present study, even though the IDC-NOS tissues exhibited significantly lower HPK1 protein. In particular, mRNA expression does not appear to be influenced by the targeted degradation of the translated protein product.

The adaptive immune system may potentially induce a beneficial antitumor immune response. Thus, the immune status of a patient may influence tumor growth, which may subsequently affect prognosis. T cells and dendritic cells are inducers and mediators of such antitumor responses (20), and HPK1 was revealed to be an important regulatory factor of $\mathrm{T}$ cell-mediated immune responses and dendritic cell activation $(21,22)$. Accordingly, results from the present study suggested a positive association between HPK1 protein expression and OS duration, which might be associated with an effect of the immune response on OS. The direct links between HPK1 expression and the immune response require further investigation in the future.

The present study, combined with previous reports, have confirmed the importance of TNM staging and axillary lymph node metastasis with respect to the survival of patients with breast cancer $(23,24)$. However, other factors, such as age and PR and HER2 expression status were not demonstrated to influence prognosis; this lack of statistical independence may be due to the small sample size and the retrospective nature of the analysis. To address these issues, future investigations will be designed with increased numbers of enrolled specimens, extend follow-up times and/or may adopt a double-blind prospective study.

In conclusion, the present study has demonstrated for the first time, to the best of our knowledge, that HPK1 protein expression, which is expressed at significantly higher levels in NATs compared with paired IDC-NOS tissues, is significantly negatively associated with ER positivity and is positively associated with OS duration, suggesting that HPK1 may exhibit anticancer activities. An increase in HPK1 protein expression in IDC-NOS tumors suggests an increased sensitivity to drug treatment and, therefore, a potential extension of OS duration. HPK1 may therefore serve as a novel and effective therapeutic target in IDC-NOS. 


\section{Acknowledgements}

The present study was supported by The Basic and Frontier Technology Research Projects of Henan Province (grant no. 152300410053) and The Young Foundation of the First Affiliated Hospital of Zhengzhou University.

\section{References}

1. Colditz GA and Bohlke K: Priorities for the primary prevention of breast cancer. CA Cancer J Clin 64: 186-194, 2014.

2. Howell A, Anderson AS, Clarke RB, Duffy SW, Evans DG, Garcia-Closas M, Gescher AJ, Key TJ, Saxton JM and Harvie MN: Risk determination and prevention of breast cancer. Breast Cancer Res 16: 446, 2014.

3. Jameera Begam A, Jubie S and Nanjan MJ: Estrogen receptor agonists/antagonists in breast cancer therapy: A critical review. Bioorg Chem 71: 257-274, 2017.

4. Chuang HC, Wang X and Tan TH: MAP4K Family Kinases in Immunity and Inflammation. Adv Immunol 129: 277-314, 2016.

5. Chen-Deutsch X, Kutner A, Harrison JS and Studzinski GP: The pan-caspase inhibitor Q-VD-OPh has anti-leukemia effects and can interact with vitamin D analogs to increase HPK1 signaling in AML cells. Leuk Res 36: 884-888, 2012.

6. Nicke B, Bastien J, Khanna SJ, Warne PH, Cowling V, Cook SJ, Peters G, Delpuech O, Schulze A, Berns K, et al: Involvement of MINK, a Ste20 family kinase, in Ras oncogene-induced growth arrest in human ovarian surface epithelial cells. Mol Cell 20: 673-685, 2005.

7. Yang HS, Matthews CP, Clair T, Wang Q, Baker AR, Li CC, Tan TH and Colburn NH: Tumorigenesis suppressor Pdcd4 down-regulates mitogen-activated protein kinase kinase kinase kinase 1 expression to suppress colon carcinoma cell invasion. Mol Cell Biol 26: 1297-1306, 2006.

8. Wang H, Song X, Logsdon C, Zhou G, Evans DB, Abbruzzese JL Hamilton SR, Tan TH and Wang H: Proteasome-mediated degradation and functions of hematopoietic progenitor kinase 1 in pancreatic cancer. Cancer Res 69: 1063-1070, 2009.

9. Alzabin S, Pyarajan S, Yee H, Kiefer F, Suzuki A, Burakoff S and Sawasdikosol S: Hematopoietic progenitor kinase 1 is a critical component of prostaglandin E2-mediated suppression of the anti-tumor immune response. Cancer Immunol Immunother 59: 419-429, 2010

10. Li Z, Park HR, Shi Z, Li Z, Pham CD, Du Y, Khuri FR, Zhang Y, Han Q and Fu H: Pro-oncogenic function of HIP-55/Drebrin-like (DBNL) through Ser269/Thr291-phospho-sensor motifs. Oncotarget 5: 3197-3209, 2014

11. Wang Y, Luo H, Li Y, Chen T, Wu S and Yang L: hsa-miR-96 up-regulates MAP4K1 and IRS1 and may function as a promising diagnostic marker in human bladder urothelial carcinomas. Mol Med Rep 5: 260-265, 2012.
12. Gradishar WJ, Anderson BO, Balassanian R, Blair SL, Burstein HJ, Cyr A, Elias AD, Farrar WB, Forero A, Giordano SH, et al: NCCN Guidelines Insights Breast Cancer, Version 1.2016. J Natl Compr Canc Netw 13: 1475-1485, 2015.

13. Webber C, Gospodarowicz M, Sobin LH, Wittekind C, Greene FL, Mason MD, Compton C, Brierley J and Groome PA: Improving the TNM classification: Findings from a 10 -year continuous literature review. Int J Cancer 135: 371-378, 2014.

14. Ogston KN, Miller ID, Payne S, Hutcheon AW, Sarkar TK, Smith I, Schofield A and Heys SD: A new histological grading system to assess response of breast cancers to primary chemotherapy: Prognostic significance and survival. Breast 12:320-327, 2003.

15. Livak KJ and Schmittgen TD: Analysis of relative gene expression data using real-time quantitative PCR and the 2(-Delta Delta C(T)) Method. Methods 25: 402-408, 2001.

16. Hosoda M, Yamamoto M, Nakano K, Hatanaka KC, Takakuwa E, Hatanaka Y, Matsuno Y and Yamashita H: Differential expression of progesterone receptor, FOXA1, GATA3, and p53 between pre- and postmenopausal women with estrogen receptor-positive breast cancer. Breast Cancer Res Treat 144: 249-261, 2014.

17. Lan T, Chen Y, Sang J, Wu Y, Wang Y, Jiang L and Tao Y: Type II cGMP-dependent protein kinase inhibits EGF-induced MAPK/JNK signal transduction in breast cancer cells. Oncol Rep 27: 2039-2044, 2012.

18. Sawasdikosol S, Zha R, Yang B and Burakoff S: HPK1 as a novel target for cancer immunotherapy. Immunol Res 54: 262-265, 2012.

19. Wang H, Chen Y, Lin P, Li L, Zhou G, Liu G, Logsdon C, Jin J, Abbruzzese JL, Tan TH and Wang H: The CUL7/F-box and WD repeat domain containing 8 (CUL7/Fbxw8) ubiquitin ligase promotes degradation of hematopoietic progenitor kinase 1 . J Biol Chem 289: 4009-4017, 2014

20. Patzak IM, Königsberger S, Suzuki A, Mak TW and Kiefer F: HPK1 competes with ADAP for SLP-76 binding and via Rap1 negatively affects T-cell adhesion. Eur J Immunol 40: 3220-3225, 2010.

21. Alzabin S, Bhardwaj N, Kiefer F, Sawasdikosol S and Burakoff S: Hematopoietic progenitor kinase 1 is a negative regulator of dendritic cell activation. J Immunol 182: 6187-6194, 2009.

22. da Cunha A, Michelin MA and Murta EF: Pattern response of dendritic cells in the tumor microenvironment and breast cancer. World J Clin Oncol 5: 495-502, 2014.

23. Wu SG, He ZY, Li Q, Sun JY, Li FY, Lin Q, Lin HX and Guan XX: Prognostic value of metastatic axillary lymph node ratio for Chinese breast cancer patients. PLoS One 8: e61410, 2013.

24. Karimi A, Delpisheh A, Sayehmiri K, Saboori H and Rahimi E: Predictive factors of survival time of breast cancer in kurdistan province of Iran between 2006-2014: A cox regression approach. Asian Pac J Cancer Prev 15: 8483-8488, 2014. 